Парыгина Наталья Николаевна

преподаватель кафедры гражданского права Омского государственного университета им. Ф.М. Достоевского

\section{ДЕЛОВАЯ РЕПУТАЦИЯ В СИСТЕМЕ НЕМАТЕРИАЛЬНЫХ БЛАГ}

\begin{abstract}
Аннотация:
В статье рассматривается деловая репутация граждан и организаций как нематериальное благо особого рода, определяется ее положение среди иных нематериальных благ. Исследуются признаки деловой репутации, проводится ее разграничение со смежными понятиями чести, достоинства, доброго имени, выводятся дефиниции названных категорий. Ставится вопрос о наборе оценок, охватываемых понятием деловой репутации.
\end{abstract}

Ключевые слова:

нематериальные блага, личные неимущественные права, деловая репутация, честь, достоинство, доброе имя, неотчуждаемость деловой репутации, неизмеримость деловой репутации.
Parygina Natalya Nikolayevna

Lecturer, Civil Law Department, Omsk State University

\section{BUSINESS REPUTATION IN THE SYSTEM OF INTANGIBLE BENEFITS}

Summary:

The article deals with personal and legal entities' business reputation as a specific intangible benefit and identifies its place among other intangible benefits. The author studies the features of business reputation, its distinction from related concepts of honor, dignity, honest name. Definitions of the noted categories are formulated. The author raises a question of values embraced by the business reputation concept.

Keywords:

intangible benefits, personal non-property rights, business reputation, honor, dignity, honest name, inalienability of business reputation, immensity of business reputation.

Положительное отражение в глазах окружающих образа любого члена общества (с появлением права и государства - субъекта права), а тем более - лица, принимающего активное участие в отношениях, связанных с гражданским оборотом, имело большое значение на самых разных, существенно отличавшихся друг от друга исторических этапах развития человечества. Применительно к правовому и социальному контексту сегодняшнего дня совершенно особый феномен представляет собой деловая репутация гражданина или юридического лица. С точки зрения юриспруденции ее дальнейшее углубленное изучение необходимо ввиду возрастающей заинтересованности граждан и организаций в ограждении своей деловой репутации от ставших гораздо более ощутимыми угроз. Вместе с тем надежная гражданско-правовая защита деловой репутации как фризических лиц, так и юридических едва ли может состояться без верного понимания природы и сущности таковой, ее единообразной легальной, правоприменительной и доктринальной интерпретации.

Относимая в ст. 150 Гражданского кодекса Российской Федерации (далее - ГК РФ) к нематериальным благам, а в ст. 128 ГК РФ в составе нематериальных благ - к объектам гражданских прав - деловая репутация нашла признание в основном источнике гражданско-правовых норм, приняв форму законодательного термина, который активно используется во многих правовых актах. Однако легальное закрепление соответствующей дефиниции отсутствует, раскрытие рассматриваемой категории оставлено за рамками официальных документов.

С течением времени неимущественным ценностям субъектов гражданских правоотношений отводится все больше места в научных исследованиях [1]. Обосновываются их самые разнообразные классификации [2]. Вместе с тем дискуссионным вопросом отечественной цивилистики остается соотношение понятий «нематериальные блага» и «личные неимущественные права». Из спектра всех имеющихся точек зрения наиболее убедительной представляется ставшая классической идея о прочной взаимосвязанности нематериальных благ и личных неимущественных прав при их однозначной нетождественности. Вызывают согласие взгляды на нематериальное благо как на объект личного неимущественного права [3, с. 40-47] и на субъективное право как на средство для обеспечения пользования благами [4, с. 613]. Если нематериальное благо (например, деловую репутацию) сравнить с чернилами, то уместной будет аналогия между стержнем, в который они заливаются (ручкой, пером), и личным неимущественным правом (по приведенному допущению - на деловую репутацию). С помощью неимущественного права полезность нематериального блага обретает форму; существование одного становится полноценным за счет другого при очевидной самостоятельности обоих явлений. 
Деловая репутация обнаруживает в себе почти все признаки нематериальных благ. Наличие лишь двух доктринально признанных свойств таких благ в приложении к ней не столь очевидно. Речь идет о традиционно вызывающих сомнения неотчуждаемости и неизмеримости репутации. Вопросы закономерно возникают в связи с присутствием в ГК РФ двух договорных конструкций. Во-первых, это коммерческая концессия (франчайзинг), предполагающая возмездное использование одной стороной соглашения (пользователем) комплекса исключительных прав, деловой репутации и коммерческого опыта другой стороны (правообладателя) (гл. 54 ГК РФ). Вовторых, обращает на себя внимание договор простого товарищества, в котором двое или несколько лиц (товарищей) принимают обязательство соединить свои вклады, в состав которых включается, в частности, деловая репутация (гл. 55 ГК РФ). В п. 2 ст. 1042 ГК РФ предусмотрена денежная оценка вкладов, а значит, потенциально и деловой репутации товарищей по соглашению между ними. В самом деле, так ли неотчуждаема деловая репутация, если эффект ее преимуществ можно передать в пользование с выгодой для себя (за плату) в форме объекта концессионного соглашения или обособить в качестве самостоятельного вклада в общее дело и каким-то образом отделить от собственной правовой личности?

Думается, присутствие названных сделок в основном источнике норм отечественного гражданского права все же не должно посягать на статус нематериального блага, закрепленный за деловой репутацией в п. 1 ст. 150 ГК РФ. Так, рассматривая договор о совместной деятельности, А.М. Эрделевский признает за деловой репутацией некоторые признаки имущественного содержания, но лишь условного, ибо «деловая репутация не передается от одного участника к другому, не входит в состав общего имущества», а «ее оценка в составе вклада производится лишь для целей распределения между товарищами прибыли, общих расходов и убытков ответственности по общим обязательствам» [5, с. 147]. Относительно коммерческой концессии следует согласиться с точной трактовкой М.Н. Малеиной неотчуждаемости и непередаваемости иным способом нематериального блага как невозможности «передачи по воле управомоченного за плату или безвозмездно во временное пользование или безвозвратно именно блага, а не субъективного права на него» [6, с. 41-43]. Нет сомнений в том, что правообладатель передает контрагенту лишь право использования деловой репутации при осуществлении предпринимательской деятельности, однако отчуждение принадлежащей первоначальному и единственному носителю деловой репутации как нематериального блага не может иметь места.

Деловая репутация давно и устойчиво учитывается в составе нематериальных активов организации [7], что является подтверждением неоспоримого влияния, которое оказывает состояние репутации на материальную сферу юридического лица. На это обращается внимание и в юридической литературе: так, Е.Л. Невзгодина относит деловую репутацию (наряду с деловыми связями и положением на рынке тех или иных товаров) к особым нематериальным элементам предприятия, имеющим «большое значение при реализации предприятием своих экономических интересов, связанных с получением прибыли» [8]. Тем не менее оценка деловой репутации даже при наличии специально разработанных для этого методик по сути приблизительна. Ни о каком ее точном, в полной мере эквивалентном денежном (имущественном) отражении говорить не приходится. Этот очевидный факт в сочетании со столь же очевидной коммерческой ценностью деловой репутации делает ее поистине уникальным нематериальным благом.

Нельзя отрицать социологическое и философское происхождение и наполнение терминов «деловая репутация», «честь», «достоинство» и «доброе имя». Однако в силу того что они являются также законодательными категориями, существует необходимость в их адаптации к правовой материи, уместной будет легальная объективизация их содержания. Семантически понятия достаточно тесно связаны, через призму некоторых значений они выглядят как синонимы, пересекаются, порой объясняются одно через другое. Вместе с тем с позиций права важны уяснение вполне конкретных определений и разграничение соответствующих нематериальных благ. Опора лишь на общеупотребительное значение указанных слов в сложившейся ситуации представляется недостаточной, имеется потребность в закреплении четких юридических формулировок - возможно, в руководящем разъяснении Верховного суда Российской Федерации.

Анализ работ цивилистов показывает, что основные расхождения в квалификации родственных объектов связаны с разграничением чести и достоинства: одни ученые избирают в качестве критерия для этого субъект, формирующий оценку качеств лица, другие - основание уважительного отношения к обладателю нематериального блага. Так, при первом подходе честь понимается как общественная оценка личности (ее разных характеристик в их совокупности), а достоинство - как самооценка личности [9]. Второй подход преподносит честь как социальную оценку личности, обусловленную ее индивидуальными уникальными характеристиками, а достоинство - как некое минимальное уважение, которого заслуживает любое лицо, независимо от его поступков и качеств. Достоинство в такой интерпретации присуще всем и должно признаваться 
за каждым в одинаковом объеме. Сторонники данной концепции исходят из представления о социальном равенстве людей, из принципа равенства всех людей в моральном отношении [10]. В подтверждение такого понимания достоинства иногда приводят пункт 1 ст. 21 Конституции Российской Федерации, закрепивший охрану достоинства личности государством.

В связи с этим думается, что как первая, так и вторая трактовки имеют право не только на существование, но и на восприятие правоприменительными и законодательными органами, поскольку нематериальные блага в обеих наличествуют в объективной реальности и требуют правовой защиты. Введение отдельного термина для обозначения минимального стандарта уважения, полагающегося любому лицу (например, «ценность человеческой личности» [11, с. 18]), рискует отяготить понятийный аппарат и нормативный материал, ибо слово «достоинство» наиболее точно отражает имеющуюся в виду ценность. Кроме того, два приведенных его понимания находятся в прочной взаимосвязи: защита права личности на уважение, основанное на всеобщем равенстве людей, всегда идет рука об руку с защитой ее права на самоуважение. Поэтому видится возможным и целесообразным объединение двух указанных значений в одной категории.

При расшифровке феномена деловой репутации ученые, оперируя разными комбинациями слов, по сути единодушны. Можно сформулировать следующее определение деловой репутации, адекватное ее содержанию: нематериальное благо гражданина или юридического лица, состоящее в общественной оценке его деловых качеств в любой сфере его профрессиональной деятельности. Очевидное отличие деловой репутации от чести - в объекте оценки, которым в случае с деловой репутацией выступают характеристики определенного вида, а именно - характеристики, связанные с деловой активностью лица. Поскольку юридические лица только такими качествами и обладают, им может принадлежать лишь деловая репутация, категории чести и достоинства к организациям неприменимы.

За смежными с деловой репутацией понятиями возможно закрепить следующие определения. Честь - нематериальное благо гражданина, состоящее в даваемой обществом личности гражданина положительной оценке, обусловленной уникальным сочетанием ее индивидуальных характеристик (деяний, качеств, способностей). Достоинство - нематериальное благо гражданина, состоящее в положительной самооценке, а также в стандарте уважительного отношения со стороны общества и его отдельных членов, основанного на моральном равенстве представителей человечества.

Специалисты отмечают, что в гражданском праве отсутствует понятие репутации вообще, есть лишь категория деловой репутации [12, с. 147]. Это видится ненапрасным. Дело в том, что понятие репутации без конкретизирующего слова «деловая» станет синонимичным приведенному понятию чести. При таких обстоятельствах мало того, что нет никакого смысла говорить о репутации вообще, - наличие дублирующей категории способно привести к путанице.

Представляется, что термин «доброе имя» также не обладает самостоятельным значением. В юридической литературе имеется немало (нередко довольно убедительных) обоснований законодательного решения привести доброе имя в ст. 150 ГК РФ; в хорошо известном термине раскрываются новые нюансы и смысловые оттенки [13]. Однако полагаем, что доброе имя все же по большому счету сводимо к чести, тождественно ей и не подлежит выделению в качестве обособленно существующего нематериального блага. Упоминание о нем, напротив, заслуживает исключения из норм ГК РФ. Эта мысль также артикулировалась в научной литературе [14].

Считаем логичным мнение большинства исследователей, что слово «честь» всегда подразумевает реноме со знаком «плюс», не может иметь отрицательной коннотации [15] (это подтверждается и существованием таких выражений, как «бесчестный поступок», «бесчестный человек»). Однако в литературе представлена и противоположная точка зрения [16]. В свою очередь деловая репутация, что не оспаривается учеными, может быть как позитивной, так и негативной. Впрочем, ее качество не должно сказываться на возможности предъявления исков в ее защиту. Здесь справедливы рассуждения А.М. Эрделевского, отмечающего, что «деловая репутация потерпевшего, даже будучи плохой в сравнении с деловой репутацией других лиц, должна рассматриваться как хорошая по сравнению с ее состоянием после распространения порочащих сведений» [17, с. 117].

Необходимо принять в расчет, что деловая репутация имеет свойство формироваться на основании как истинной, так и ложной информации о ее носителе. Потому она не столь адекватна, как отражение объекта в зеркале, а, наоборот, не носит на 100 \% объективного характера. Кроме того, деловая репутация подвижна, т. е. имеет постоянную тенденцию к изменениям, динамике [18]. Учитывая эти факты, нельзя не отметить значение самостоятельных действий субъекта - носителя деловой репутации по ее благополучному складыванию, а в дальнейшем - по ее поддержанию на должном уровне [19, с. 29, 43]. Предприниматели-производители из отдельных государств, успешно зарекомендовавшие себя на мировом рынке благодаря высокому качеству своих товаров, 
в определенной степени создают положительную деловую репутацию для предпринимателей-соотечественников, если добиваются того, что их отличающаяся превосходством продукция начинает ассоциироваться у потребителей мира с конкретной страной.

Утверждение, что деловая репутация подразумевает общественную оценку деловых качеств лица, стоит сопроводить ремаркой: деловые качества - не то же, что качества предпринимательские, подобное их понимание было бы неоправданно зауженным. Обладателями такого нематериального блага, как деловая репутация, наряду с коммерческими юридическими лицами и индивидуальными предпринимателями являются некоммерческие организации и граждане, не обладающие указанным особым статусом, так как общественное мнение о деловых характеристиках лица складывается в сфере не только бизнеса, но и деятельности любого другого рода. Корректность и практичность выделения в качестве самостоятельных явлений профессиональной или служебной репутации [20] сомнительны [21].

О.Ш. Аюпов в зону охвата деловой репутации включает оценку не только профессиональных, но и иных социально значимых качеств субъекта. Автор аргументирует это тем, что «в современном мире деловая репутация не может ограничиваться только сферой профессиональной деятельности» [22]. Если имеются в виду качества, которые напрямую не относятся к главному виду деятельности лица, возражений не возникает, однако если речь об иных потенциально социально значимых свойствах (например, моральных характеристиках), спешить с выводами не стоит. Допустим, индивидуальному предпринимателю приписывают неэтичное поведение с друзьями, склонность подводить или обманывать товарищей. Эти качества находятся в плоскости нравственности; ложность обвинений, предположим, в конкретном фракте обмана должна оспариваться в рамках защиты чести. Если описанный порок проявится в нечестных поступках по отношению к партнеру по бизнесу или попросту в мошенничестве применительно к любым лицам, что предсказуемо даст основания опасаться за сотрудничество с предпринимателем как с профессионалом, - моральное (точнее, аморальное) качество приобретет форму делового и, следовательно, будет пятнать уже деловую репутацию лица.

Таким образом, деловая репутация все же имеет дело с оценкой именно и исключительно профессиональных свойств и компетенций или их отсутствия. Помимо прочего, обратное затруднило бы разграничение деловой репутации как профессиональной характеристики и чести как всевозможных иных характеристик благообладателя. Вместе с тем здравомыслие усматривается и в тезисе о том, что в процессе защиты чести и достоинства происходит (пусть и косвенно) защита деловой репутации, поскольку «воздействие на честь и достоинство неизбежно влияет на мнение окружающих о деловых качествах лица» [23, с. 33]. Думается, хотя и не всегда, но, действительно, достаточно часто распространение нелестных сведений, затрагивающих два первых блага, сказывается на последнем.

Итак, деловая репутация представляет собой мультиаспектное, многогранное явление, имеющее прежде всего социологическую, а также фрилософскую, экономическую, правовую и даже деонтологическую составляющие, ни одну из которых нельзя игнорировать.

Неоспоримая коммерческая ценность деловой репутации для организаций и индивидуальных предпринимателей (как и имущественная ценность деловой репутации для любых граждан, занимающихся любой профессиональной деятельностью) сочетается с условностью ее оценки, невозможностью вывести ее точный денежный эквивалент. Допустимо отчуждение права использования деловой репутации, но не отчуждение ее самой. Деловая репутация как нематериальное благо с особыми свойствами требует отдельного доктринального изучения и особой законодательной регламентации.

\section{Ссылки и примечания:}

1. См., например: Андреев В.К. Существо нематериальных благ и их защита // Журнал российского права. 2014 . № 3. С. 27-33 ; Арзуманян А.Б. Нематериальные блага как объекты гражданских прав : автореф. дис. ... канд. юрид. наук. Краснодар, 2008 ; Борычева Т.А. Понятие и правовая природа нематериальных благ юридических лиц // Юридический мир. 2012. № 9. С. 30-32 ; Вешкурцева 3.В. Структурные подходы к определению понятий «нематериальные блага» и «личные неимущественные права» // Актуальные проблемы российского права. 2014. № 2. С. 225-234 ; Ермолова О.Н., Трофименко А.В. Проблемы теории нематериальных благ. М., 2008 ; Захаров Н. Нематериальные блага и их защита // ЭЖ-Юрист. 2014. № 9. С. 4 ; Костюк В.Д. Нематериальные блага. Защита чести, достоинства и деловой репутации. М., 2002 ; Малеина М.Н. Понятие и виды нематериальных благ как объектов личных неимущественных прав // Государство и право. 2014. № 7. С. 40-47 ; Тимешов Р.П. Нематериальные блага в гражданском праве и их защита : автореф. дис. ... канд. юрид. наук. Краснодар, 2010 ; Трофимова Т.В. Нематериальные блага юридических лиц и их гражданско-правовая защита // Вестник ОмГУ. Сер. «Право». 2009. № 3. С. $244-248$.

2. См., например: Кожевина Е.В. Нематериальные блага как объект гражданских прав: дискуссионные вопросы теории и судебное толкование // Цивилист. 2010. № 4. С. 59-63 ; Красавчикова Л.О. Понятие и система личных неимущественных прав граждан в гражданском праве Российской Федерации : автореф. дис. ... канд. юрид. наук. Екатеринбург, 1994. С. 14-25 ; Сахапов Ю.3. Деловая репутация субъектов предпринимательской деятельности в системе объектов гражданских прав и особенности ее гражданско-правовой защиты : дис. ... канд. юрид. наук. Казань, 2007. 
С. 9 ; Тюленев И.В. Защита чести, достоинства и деловой репутации по российскому и международному законодательству : дис. ... канд. юрид. наук. М., 2010. С. 12.

3. См.: Малеина М.Н. Указ. соч. С. 40-47.

4. См.: Шершеневич Г.Ф. Общая теория права. М., 1912. С. 613.

5. Эрделевский А.М. Компенсация морального вреда: анализ и комментарий законодательства и судебной практики. М., 2007. С. 147

6. Малеина М.Н. Указ. соч. С. 41-43.

7. См.: Об утверждении Положения по бухгалтерскому учету «Учет нематериальных активов» (ПБУ 14/2007) : приказ Минфина России от 27 дек. 2007 г. № 153н // Российская газета. 2008. 2 февр. (Аналогичные тезисы содержались и в предшествовавшем документе - Учет нематериальных активов : положение по бухгалтерскому учету (ПБУ 14/2000) : приказ Минфина России от 16 окт. 2000 г. № 91н). См. также: Приказ Минэкономразвития России от 22 июня 2015 г. № 385 // Вестник образования России. 2015. № 19 ; Письмо Банка России от 21 июля 2011 г. № 110-Т // Там же. 2011. № 41.

8. См.: Невзгодина Е.Л.: 1) Сделки с недвижимостью (понятие, виды, правовое регулирование) : учеб. пособие / под ред. А.И. Казанника. 2-е изд., доп. Омск, 2004. С. 210 ; 2) Правовой режим предприятия как недвижимое имущество // Вестник ОмГУ. Сер. «Право». 2007. № 2 (11). С. 59.

9. См.: Быковский В.В. Гражданско-правовая защита физических и юридических лиц при распространении о них сведений, порочащих их честь, достоинство и деловую репутацию : дис. ... канд. юрид. наук. М., 2005. С. 9 ; Гражданское право [Электронный ресурс] : учеб. В 2 т. / С.С. Алексеев, О.Г. Алексеева, К.П. Беляев и др. ; под ред. Б.М. Гонгало. Т. 1. М., 2016. Доступ из справ.-правовой системы «КонсультантПлюс».

10. См.: Иваненко Ю.Г. Актуальные вопросы защиты чести, достоинства и деловой репутации граждан и юридических лиц : дис. ... канд. юрид. наук. М., 1998. С. 20-21 ; Кузнецов Н.М. Содержание отношений по защите чести, достоинства и деловой репутации : дис. ... канд. юрид. наук. М., 2009. С. 12.

11. Кузнецов Н.М. Указ. соч. С. 18.

12. См., например: Потапенко С.В. Судебная защита от диффрамации в СМИ. Краснодар, 2002. С. 147.

13. См.: Килинкаров В.В. Право на деловую репутацию субъектов предпринимательской деятельности : дис. ... канд. юрид. наук. СПб., 2011. С. 32 ; Кузнецов Н.М. Указ. соч. С. 18 ; Эрделевский А.М. Указ. соч. С. 116-117.

14. См.: Аюпов О.Ш. Защита деловой репутации юридического лица от диффамации в гражданском праве России : автореф. дис. ... канд. юрид. наук. Томск, 2013. С. 13 ; Малеина М.Н. Указ. соч. С. 40-47.

15. См., например: Барсукова В.Н. Честь и достоинство личности: понятие и общая характеристика // Современное право. 2014. № 12. С. 20-25 ; Килинкаров В.В. Указ. соч. С. 31-32 ; Кузнецов Н.М. Указ. соч. С. 12 ; Рожкова М.А. Обязательство по компенсации репутационного ущерба как разновидность деликтного обязательства // Обязательства, возникающие не из договора : сборник статей / Ф.Х. Альманса Монтойя, А.А. Амангельды, Д.В. Афанасьев и др. ; отв. ред. М.А. Рожкова. М., 2015 ; Тимошенко В.А., Смушкин А.Б. Комментарий к Закону РФ от 27 дек. 1991 г. № 2124-1 «О средствах массовой информации» (постатейный) [Электронный ресурс]. Доступ из справ.-правовой системы «КонсультантПлюс».

16. См.: Быковский В.В. Указ. соч. С. 9 ; Малеина М.Н. Указ. соч. С. 40-47.

17. Эрделевский А.М. Указ. соч. С. 117

18. Данные обстоятельства признаны в научных работах. См., например: Ершова Е.А. Гудвилл бизнеса. М., 2013. С. 1112 ; Иваненко Ю.Г. Указ. соч. С. 110 ; Килинкаров В.В. Указ. соч. С. 22.

19. См. по этому вопросу: Супрунов А.Г. Правовая защита деловой репутации по законодательству современной России: общетеоретический аспект : дис. ... канд. юрид. наук. Н. Новгород, 2009. С. 29, 43.

20. См.: Гусалова А.Р. Гражданско-правовая защита деловой репутации : автореф. дис. ... канд. юрид. наук. Владикавказ, 2012. С. 6-7, 10 ; Плотников В. Деловая репутация как объект гражданско-правовой защиты // Хозяйство и право. 1995. № 11. C. 38 .

21. В этом мнении солидарны многие авторы. См., например: Иваненко Ю.Г. Указ. соч. С. 102 ; Супрунов А.Г. Указ. соч. С. 31-32 ; Фроловский Н.Г. Защита деловой репутации юридического лица // Законы России: опыт, анализ, практика. 2012. № 4. С. 49-50.

22. Аюпов О.Ш. Указ. соч. С. 10-11. Созвучно приведенному мнение О.А. Кулиуша, понимающего под деловой репутацией не только оценку деловых качеств юридического лица, но и целостную оценку всей его деятельности. (См.: Кулиуш О.А. Защита деловой репутации субъектов предпринимательской деятельности : дис. .... канд. юрид. наук. М., 2011. С. 53-54).

23. См.: Килинкаров В.В. Указ. соч. С. 33.

\section{References:}

Alekseev, SS, Alekseeva, OG, Belyaev, KP (etc.) \& Gongalo, BM (ed.) 2016, Civil law, textbook, in 2 vols., vol. 1, Moscow, (in Russian).

Andreev, VK 2014, 'Nature of Intangible Benefits and Their Protection', Zhurnal rossiyskogo prava, no. 3, pp. 27-33, https://doi.org/10.12737/2577.

Arzumanyan, AB 2008, Intangible benefits as objects of civil rights, PhD in Law thesis abstract, Krasnodar, (in Russian).

Ayupov, OSh 2013, Protection of the business reputation of a legal entity from defamation in the civil law of Russia, PhD in

Law thesis, Tomsk, p. 13, (in Russian).

Barsukova, VN 2014, 'Personal honor and dignity: the concept and the general description', Sovremennoye parvo, no. 12, pp. 20-25, (in Russian).

Borycheva, TA 2012, 'Concept and legal nature of intangible benefits of legal entities', Yuridicheskiy mir, no. 9, pp. 30-32, (in Russian).

Bykovsky, VV 2005, Civil legal protection of individuals and legal entities in the dissemination of information about them, discrediting their honor, dignity and business reputation, $\mathrm{PhD}$ in Law thesis, Moscow, p. 9, (in Russian).

Erdelevsky, AM 2007, Compensation for moral damages: legal and judicial practice comments and analysis, Moscow, p. 147, (in Russian).

Ermolova, ON \& Trofimenko, AV 2008, Problems of the theory of intangible benefits, Moscow, (in Russian).

Ershova, EA 2013, Business goodwill, Moscow, pp. 11-12, (in Russian).

Frolovsky, NG 2012, 'Protection of business reputation of a legal entity', Zakony Rossii: opyt, analiz, praktika, no. 4, pp. 4950, (in Russian).

Gusalova, AR 2012, Civil legal protection of business reputation, PhD in Law thesis abstract, Vladikavkaz, pp. 6-7, 10, (in Russian). 
Ivanenko, YuG 1998, Topical issues on protection of honor, dignity and business reputation of citizens and legal entities, $\mathrm{PhD}$ in Law thesis, Moscow, pp. 20-21, (in Russian).

Kilinkarov, VV 2011, The right to business reputation of business entities, PhD in Law thesis, St.-Petersburg, p. 32, (in Russian).

Kostyuk, VD 2002, Intangible benefits. Protection of honor, dignity and business reputation, Moscow, (in Russian).

Kozhevina, EV 2010, 'Intangible benefits as an object of civil rights: debating points of theory and judicial interpretation',

Tsivilist, no. 4, pp. 59-63, (in Russian).

Krasavchikova, LO 1994, The concept and system of personal non-property rights of citizens in the civil law of the Russian

Federation, $\mathrm{PhD}$ in Law thesis abstract, Ekaterinburg, pp. 14-25, (in Russian).

Kuliush, OA 2011, Protection of business reputation of business entities, PhD in Law thesis, pp. 53-54, (in Russian).

Kuznetsov, NM 2009, The content of relations for the protection of honor, dignity and business reputation, $\mathrm{PhD}$ in Law thesis,

Moscow, p. 12, (in Russian).

'Letter of the Bank of Russia No. 110-T dated July 21, 2011' 2011, Vestnik obrazovaniya Rossii, no. 41, (in Russian).

Maleina, MN 2014, 'The concept and types of intangible benefits as objects of personal non-property rights', Gosudarstvo i parvo, no. 7, pp. 40-47, (in Russian).

Nevzgodina, EL \& Kazannik, Al (ed.) 2004, Real estate transactions (concept, types, legal regulation), textbook, 2nd ed.,

Omsk, p. 210, (in Russian).

Nevzgodina, EL 2007, 'Legal order of the enterprise as a real estate', Vestnik OmGU. Ser. "Pravo", no. 2 (11), p. 59, (in Russian).

'On approval of the Accounting Regulations "Accounting for Intangible Assets" (PBU 14/2007): Order of the Russian Ministry

of Finance No. 153n dated December 27, 2007' 2008, Rossiyskaya gazeta, February 2, (in Russian).

'Order of the Ministry of Economic Development of Russia No. 385 dated June 22, 2015' 2015, Vestnik obrazovaniya Rossii, no. 19, (in Russian).

Plotnikov, V 1995, 'Business reputation as an object of civil legal protection', Khozyaystvo i parvo, no. 11, p. 38, (in Russian). Potapenko, SV, Judicial protection from defamation in mass media, Krasnodar, p. 147, (in Russian).

Rozhkova, MA, Almansa Montoya, FKh, Amangeldy, AA, Afanasyev, DV (etc.) 2015, 'Obligation for reputational damage compensation as a kind of delictual obligation', Obyazatel'stva, voznikayushchiye ne iz dogovora, collection of articles, Moscow, (in Russian).

Sakhapov, YuZ 2007, Business reputation of business entities in the system of civil rights objects and features of its civil legal protection, PhD in Law thesis, Kazan, p. 9, (in Russian).

Shershenevich, GF 1912, General theory of law, Moscow, p. 613, (in Russian).

Suprunov, AG 2009, Legal protection of business reputation under the laws of modern Russia: the general theoretical aspect,

$\mathrm{PhD}$ in Law thesis, Nizhny Novgorod, pp. 29, 43, (in Russian).

Timeshov, RP 2010, Intangible benefits in civil law and their protection, PhD in Law thesis abstract, Krasnodar, (in Russian). Trofimova, TV 2009, 'Intangible benefits of legal entities and their civil legal protection', Vestnik OmGU. Ser. "Pravo", no. 3, pp. 244-248, (in Russian).

Tyulenev, IV 2010, Protection of honor, dignity and business reputation under Russian and international law, PhD in Law thesis, p. 12, Moscow, (in Russian).

Veshkurtseva, ZV 2014, 'Structural approaches to the definition of "intangible benefits" and "personal non-property rights", Aktual'nyye problemy rossiyskogo prava, no. 2, pp. 225-234, https://doi.org/10.7256/1994-1471.2014.2.10235.

Zakharov, N 2014, 'Intangible benefits and their protection', EZh-Yurist, no. 9, p. 4, (in Russian). 